\title{
The effect of bystander CPR on survival of out-of-hospital cardiac arrest victims
}

\begin{abstract}
The effect of bystander cardiopulmonary resuscitation (CPR) was studied in 2142 emergency medical service (EMS) cardiac arrest runs. When bystander CPR was administered to cardiac arrest victims, $22.9 \%$ of the victims survived until they were admitted to the hospital and $11.9 \%$ were discharged alive. In comparison, the statistics for cardiac arrest victims who did not receive bystander CPR were $14.6 \%$ and $4.7 \%$, respectively $(p<0.001)$. A critical factor in patient survival was the amount of time that elapsed before the EMS personnel arrived and administered CPR. Patients who received bystander CPR were more likely to have ventricular fibrillation when the EMS arrived. Other factors relating to patient survival were the location of the victim at the time of the cardiac arrest and the age of the victim. Understanding these factors is important in developing community strategies to treat patients with cardiac arrest out of hospital. (AM HEART J 110:932, 1985.)
\end{abstract}

George Ritter, M.D., Robert A. Wolfe, Ph.D., Sidney Goldstein, M.D., J. Richard Landis, Ph.D., C. Mark Vasu, M.D., Allyn Acheson, B.S., Richard Leighton, M.D., and Sharon VanderBrug Medendrop, M.P.H. Detroit and Ann Arbor, Mich.

In 1960 , Kouwenhoven et al. ${ }^{1}$ reported that it was possible to sustain life in patients whose hearts had stopped as long as 30 minutes by means of chest compression combined with mouth-to-mouth respiration (CPR). This period of temporary support was effective in sustaining life until endotracheal intubation and cardiac defibrillation or pacing could be carried out. Originally, CPR was employed in the hospital setting, where equipment and trained personnel were immediately available. Despite concern about nonmedical personnel administering CPR, the positive experience in the hospital setting resulted in expansion of CPR to include the victims of out-of-hospital cardiac arrests. Concurrent with the introduction of CPR, emergency medical services (EMS) were developed in Europe and North America to bring medical care to the victims of cardiac arrest that occurred outside the hospital. ${ }^{2-4}$ As both training of lay persons in CPR and the deployment of EMS units expanded, the potential for patient survival after out-of-hospital cardiac arrest improved. The possibility that these two

From the Department of Medicine, Division of Cardiovascular Medicine, Henry Ford Hospital, and the Department of Biostatistics, University of Michigan.

This study was supported by NHLBI, \#HL188000-09.

Received for publication May 6, 1985; accepted June 5, 1985.

Reprint requests: Dr. Sidney Goldstein, Henry Ford Hospital, Division of Cardiovascular Medicine, 2799 W. Grand Boulevard, Delroit, MI 48202. modalities of emergency treatment have improved the survival rate for cardiac arrest victims has been supported by a number of investigations. ${ }^{5.9}$

This study provides additional reasons for the training of citizens in CPR coupled with the use of EMS. In addition, some of the demographic and logistic factors that affect patient survival outof-hospital cardiac arrest will be discussed. This is based on a multivariable analysis of data collected in the study of three communities over a 5-year period.

\section{METHODS}

All of the emergency cardiac arrest runs of EMS in Lucas County, Ohio, and in Kent County, and Southfield, Michigan, that occurred between September, 1977, and July, 1982, were included in the study. Southfield was a suburban community with a population density of 2700 persons per square mile and Lucas and Kent Counties had population densities of 1400 and 500 , respectively. In the 59 months included in this study, 2849 cardiac arrest runs were undertaken. Complete data were available on 2142 EMS runs. Initial information was collected on a standard form which was completed by an EMS technician and subsequently reviewed by the nurse coordinator of the study. Discharge status of the patient was obtained by the nurse coordinator. The data collected for each EMS run included the age and sex of the patient, location of the cardiac arrest, response time of the EMS, whether or not CPR was applied, and by whom, patient's cardiac rhythm at the time the EMS arrived, survival status of the patient 
Table I. CPR survival rates $(n=2142)$

\begin{tabular}{lccc}
\hline $\begin{array}{c}\text { Administration } \\
\text { of CPR }\end{array}$ & $\begin{array}{c}\text { Percent } \\
\text { of } \\
\text { sample }\end{array}$ & $\begin{array}{c}\text { Percent } \\
\text { admitted } \\
\text { alive* }\end{array}$ & $\begin{array}{c}\text { Percent } \\
\text { discharged } \\
\text { alive }\end{array}$ \\
\hline None & 63.8 & 14.6 & 4.7 \\
$\begin{array}{l}\text { Bystander } \\
\text { Cardiac arrest after } \\
\quad \text { arrival }\end{array}$ & 14.2 & 32.5 & 17.4 \\
Overall & 100.0 & 19.0 & 8.1 \\
\hline
\end{tabular}

${ }^{*}$ Chi square $=59.0, p<0.001$.

tChi square $=65.8, p<0.001$

to the hospital, and final discnarge status. Patients who survived for 60 minutes or less after they arrived at the hospital were considered to be dead on arrival; patients who survived longer than 60 minutes were considered to be alive on arrival. Patients who were discharged alive from the receiving hospital and returned home or patients who were transferred to a rehabilitation facility were defined as discharged alive.

In 305 out of 2142 instances, cardiac arrest occurred after the EMS arrived and emergency care which included intubation and defibrillation was immediately instituted. These patients, defined as having arrest after arrival (AAA) received optimal emergency care in the field and are the standard for measurement of the effect of CPR and EMS response time.

Statistical hypothesis tests and estimates were based on the chi square statistic, quadratic least squares regression, analysis of covariance, analysis of variance, logistic regression, Kaplan-Meier survival curves, and the log-rank test. The test for equality of regression coefficients in analysis of covariance indicated that the coefficients for the four models shown in Fig. 1 were significantly different from each other $(p<0.01)$; therefore the models were estimated independently of each other. Multivariable logistic regression analysis was employed to demonstrate the simultaneous relationship between survival rates and several risk factors. The results that are reported in Fig. 2 are based on a logistic model with a linear adjustment for age and with indicator variables for various response times. Comparable results were obtained by means of a logistic model with a quadratic adjustment for age. A similar model with a linear function of response time compared mortality rates of AAA subjects to hypothetical subjects with a 0 -minute response time. The survival curves reported in Fig. 3 are Kaplan-Meier estimates.

\section{RESULTS}

The overall survival rates of the patients who received bystander CPR are shown in Table 1. Bystander CPR was administered to $472(22 \%)$ of the patients in the study; this resulted in more patients being admitted to the hospital and discharged alive as compared to patients who did not receive CPR. Bystander CPR resulted in nearly a

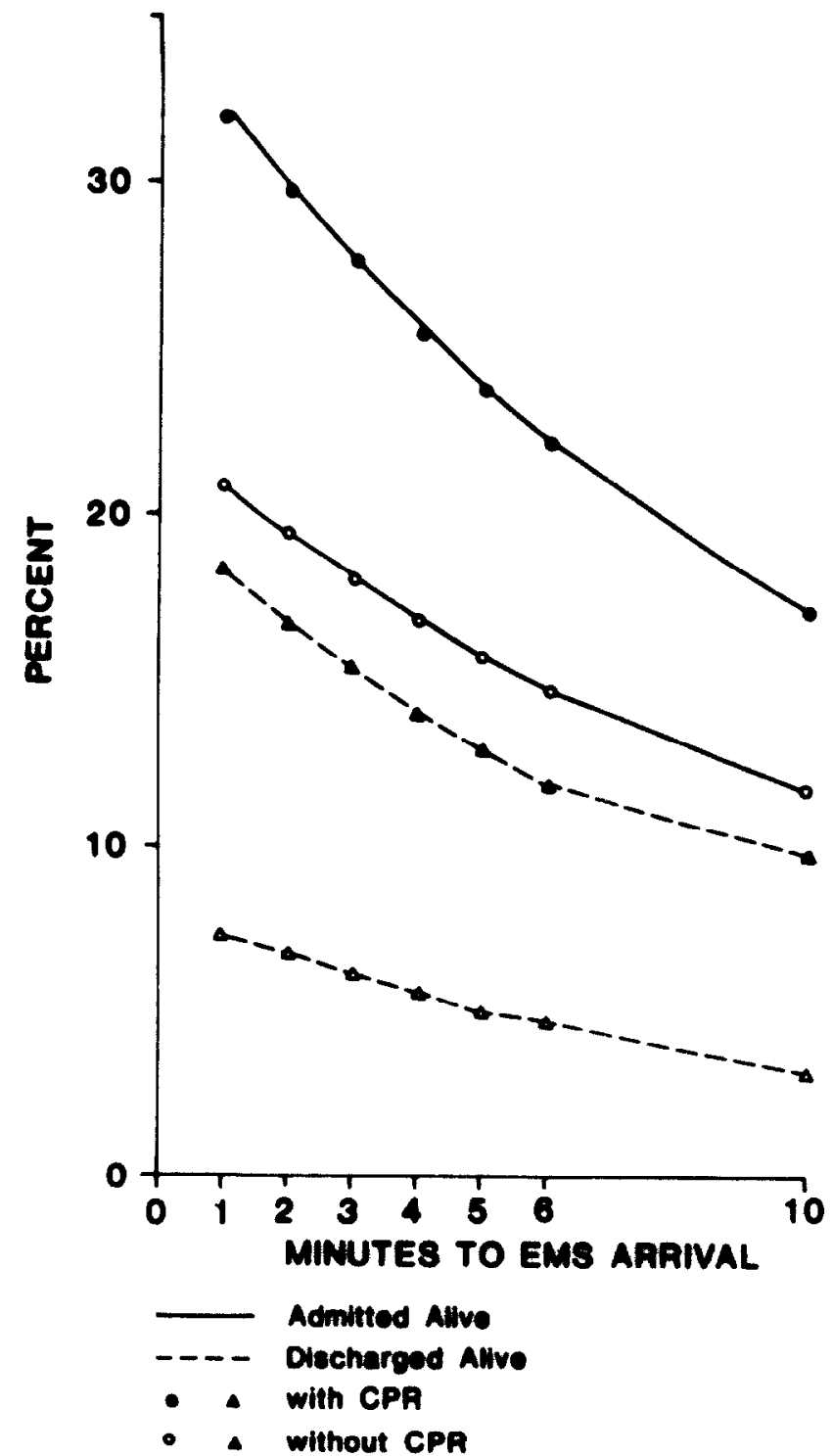

Fig. 1. Least squares regression model relating the dichotomous survival outcome to quadratic functions of EMS response time separately for those with and without CPR. There was no evidence of a significant lack of fit for any of the four models $(p>0.05)$.

threefold increase in patients who were discharged alive-11.9\% compared to $4.7 \%(p<0.001)$. Of the personnel providing bystander CPR, $25 \%$ were classified as health professionals. Although the survival rate was higher in patients who received CPR than in patients who did not receive CPR, it was not as high as the $17.4 \%$ survival rate of patients who experienced cardiac arrest after the arrival of the EMS (AAA). These AAA patients represented $14.2 \%$ of the study patients; $19 \%$ were alive when they arrived at the hospital and $8.1 \%$ were discharged from the hospital alive. 
Table II. EMS response time and survival rates

\begin{tabular}{lcccc}
\hline $\begin{array}{c}\text { Response time } \\
\text { (minutes) }\end{array}$ & $\begin{array}{c}\text { Percent } \\
\text { of sample }\end{array}$ & $\begin{array}{c}\text { Percent receiving } \\
\text { bystander CPR }\end{array}$ & $\begin{array}{c}\text { Percent } \\
\text { admitted alivet }\end{array}$ & $\begin{array}{c}\text { Percent } \\
\text { discharged alive } \neq\end{array}$ \\
\hline Cardiac arrest after arrival & 14.2 & - & 32.5 & 17.4 \\
One & 5.2 & 36.0 & 26.5 & 13.5 \\
Two & 9.7 & 30.8 & 24.0 & 10.6 \\
Three & 13.5 & 27.2 & 21.4 & 8.3 \\
4 to 5 & 28.2 & 23.2 & 16.9 & 6.3 \\
6 or more & 29.2 & 23.8 & 10.2 & 3.4 \\
Overall & 100.0 & 25.7 & 19.0 & 8.1 \\
\hline
\end{tabular}

*Among 1837 patients who did have cardiac arrest after hospital arrival; chi-square $=12.4, p<0.05$.

†Chi square $=77.1, p<0.001$.

tChi square $=63.0, p<0.001$.

Table III. Age and survival rate

\begin{tabular}{rcccc}
\hline Age & $\begin{array}{c}\text { Percent } \\
\text { of sample }\end{array}$ & $\begin{array}{c}\text { Percent receiving } \\
\text { bystander CPR }\end{array}$ & $\begin{array}{c}\text { Percent } \\
\text { admitted alive† }\end{array}$ & $\begin{array}{c}\text { Percent } \\
\text { discharged alive }\end{array}$ \\
\hline 39 & 3.1 & 31.7 & 19.7 & 10.6 \\
$40-49$ & 8.6 & 33.8 & 17.3 & 12.4 \\
$50-59$ & 18.9 & 31.6 & 18.0 & 8.6 \\
$60-69$ & 31.2 & 24.5 & 20.9 & 9.9 \\
$70-79$ & 26.3 & 22.2 & 19.7 & 6.7 \\
$80+$ & 11.8 & 18.6 & 14.6 & 1.6 \\
\hline
\end{tabular}

*Among 1837 patients who were not AAA; chi square $=21.8, p<0.001$.

+ Chi square $=5.5$, ns.

†Chi square $=241, p<0.001$.

The relationship between the time for the EMS to respond and the overall survival rates of the patients in the study is shown in Table II. The survival rates for AAA subjects are also shown for comparison purposes. The mean EMS response time was 5.3 minutes (median 4 minutes) for the 1837 subjects who did not experience AAA. Fig. 1 shows the decrease in the proportion of patients who are admitted alive and patients who are discharged alive when the response time of the EMS lengthens. Also shown is the profound effect on patient survival rate of bystander CPR. Table II shows the percent of patients admitted to the hospital alive $(32.5 \%)$ and discharged alive $(17.4 \%)$; these percentages approximate the rates shown in Fig. 1 for patients who received CPR with 1-minute EMS response times. Patient survival rates almost doubles when bystander CPR is applied.

Other characteristics were also examined; these included age and sex of the patient and the location of the patient when the EMS received the call. The prognosis was relatively good for the younger patient (Table III). Approximately $20 \%$ of patients up to the age of 80 years were admitted to the hospital alive, but this decreased to less than $15 \%$ of the patients over 80 years; only a small number of these patients were discharged alive. A similar decrease was seen in patients discharged alive in the over-70 group of patients $(p<0.001)$. There was a concomitant decrease in the number of older patients who received bystander CPR $(p<0.001)$.

It was significant that women were more likely to be admitted alive than men $(p<0.001)$. However, there were fewer women discharged alive $(p=N S)$ (Table IV). The patient's location at the time of the cardiac arrest is significant (Table V). Victims who suffered cardiac arrest at work were more likely to receive bystander CPR $(62.7 \%)$ and be discharged from the hospital alive $(21.7 \%)$ than victims who suffered cardiac arrest at home $(18.2 \%$ and $6.4 \%$ respectively). Patients who experienced cardiac arrest in a public place had intermediate percentage values. The average EMS response time was shortest (4.1 minutes) for patients who experienced cardiac arrest at work, about 0.5 minute longer ( 4.7 minutes) for patients who experienced cardiac arrest in other public places, and longest (5.5 minutes) for patients who experienced cardiac arrest at home $(p<0.0001)$.

Cardiac rhythm of patients when the EMS arrived is shown in Table VI. Ventricular fibrillation was the most common rhythm at arrival. Asystolic patients were less likely to survive until discharge from the hospital than were patients with other initial 
Table IV. Sex and survival rates

\begin{tabular}{ccccc}
\hline Sex & $\begin{array}{c}\text { Percent } \\
\text { of sample }\end{array}$ & $\begin{array}{c}\text { Percent receivin } \\
\text { bystander CPR }\end{array}$ & $\begin{array}{c}\text { Percent } \\
\text { admitted alivet }\end{array}$ & $\begin{array}{c}\text { Percent } \\
\text { discharged aliver }\end{array}$ \\
\hline Women & 26.9 & 21.9 & 24.3 & 6.9 \\
Men & 73.1 & 26.9 & 17.0 & 8.5 \\
\hline
\end{tabular}

${ }^{*}$ Among $18: 37$ patients who were not AAA; chi square $=4.5, p<0.05$.

tChi square $-14.7, p<0.001$.

tChi square $=1.4$, ns.

Table $V$, Location of arrest and survival rates

\begin{tabular}{lcccc}
\hline $\begin{array}{c}\text { Location } \\
\text { of call }\end{array}$ & $\begin{array}{c}\text { Percent } \\
\text { of sample }\end{array}$ & $\begin{array}{c}\text { Percent receiving } \\
\text { bystander CPR }\end{array}$ & $\begin{array}{c}\text { Percent } \\
\text { admitted alivet }\end{array}$ & $\begin{array}{c}\text { Percent } \\
\text { discharged alivet }\end{array}$ \\
\hline Home & 76.5 & 18.2 & 17.9 & 6.4 \\
Public place & 20.3 & 44.5 & 21.4 & 13.2 \\
Work & 3.2 & 62.7 & 29.0 & 21.7 \\
Overall & 100.0 & 25.7 & 19.0 & 8.1 \\
\hline
\end{tabular}

${ }^{*}$ Among 1837 patients who were not AAA; chi square $=163.6, p<0.0001$.

tChi square $=7.5, p<0.05$.

tChi square $=33.5, p<0.001$.

Table VI. CPR and cardiac rhythm at EMS arrival $(n=1837)$

\begin{tabular}{lcccc}
\hline \multicolumn{1}{c}{ Cardiac rhythm } & $\begin{array}{c}\text { Percent } \\
\text { of sample }\end{array}$ & $\begin{array}{c}\text { Percent receiving } \\
\text { bystander CPR }\end{array}$ & $\begin{array}{c}\text { Percent } \\
\text { admitted alivet }\end{array}$ & $\begin{array}{c}\text { Percent } \\
\text { dicharged alivet }\end{array}$ \\
\hline Ventricular tachycardia & 3.1 & 21.1 & 24.6 & 10.5 \\
Ventricular fibrillation & 63.5 & 28.4 & 20.0 & 8.5 \\
Complete heart block & 1.0 & 17.6 & 29.4 & 17.6 \\
Asystole & 32.4 & 21.0 & 9.2 & 2.0 \\
\hline
\end{tabular}

${ }^{*}$ Chi square $=12.8, p<0.01$.

† Chi square $=37.4 . p<0.0001$

tChi square $=32.1, p<0.0001$.

rhythms $(p<0.01)$. The initial cardiac rhythm in $73 \%$ of the patients who received bystander CPR was ventricular fibrillation or tachycardia as compared to $64 \%$ of the patients who did not receive bystander CPR. $(p<0.01)$

Fig. 2 shows the results of fitting multivariable logistic models in order to predict the percent of patients discharged alive from the hospital; these are based on several factors including CPR administration, response time, age, sex, and location of call. This figure is based on the "typical" patient who is characterized as a 65-year-old man whose cardiac arrest occurred in a public place, who received bystander CPR, and who received EMS treatment with a response time of 4 minutes. The AAA patients were also included in the analysis for comparative purposes. This figure shows the relative effects of changing one factor at a time while all of the other factors remain the same. Each factor shown as a vertical line indicates the relative size of its effect on survival rates (an appropriate multiple of the logistic regression coefficient). For example, the model predicts that the survival rate for typical patients who receive CPR is $13 \%$ with a 1 -minute response time and $8 \%$ with a 4 - to 5-minute response time. The model also shows that the survival rate for a typical patient whose cardiac arrest occurs at work would be $17.5 \%$; for a typical patient whose cardiac arrest occurs at home, it would be only $7 \%$. The age and sex of the patient have relatively smaller effects on survival rates. Response time, CPR, location of call, and age were significantly related to discharged-alive rates $(p<0.05)$. Sex was not significantly related to discharged-alive status $(p>0.05)$. The model shows that the effect of bystander CPR on patient survival to discharge from the hospital is equivalent to the effect of a 4-minute-earlier EMS response time. Therefore, CPR is a substantial and significant predictor of survival above and beyond any differences between patients who receive or do not receive CPR with respect to response time, age, etc. However CPR 


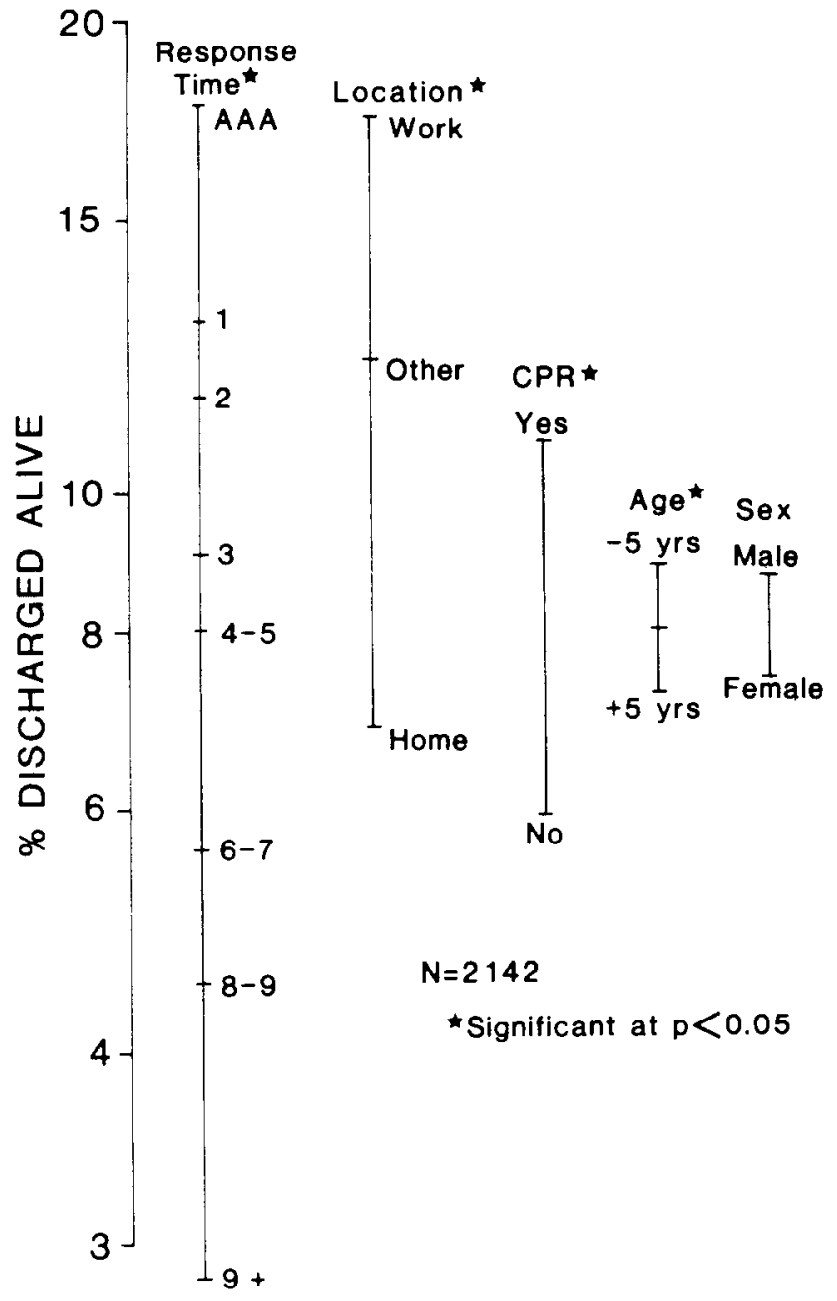

Fig. 2. Relative effects of various factors on percent discharged alive are shown. Response time is in minutes, and corresponding survival rates are reported for those receiving bystander CPR. AAA denotes patients who suffered cardiac arrest after arrival. The effect of age is shown 5 years younger and older than the mean of the total study population.

does not have any residual effect on long-term survival after discharge from the hospital (Fig. 3).

\section{DISCUSSION}

The results of this study support the reports of previous investigators that indicate the value of both CPR and EMS for victims whose cardiac arrest occurs outside the hospital. ${ }^{5-8}$ It also indicates some of the logistic problems inherent in providing community emergency treatment of cardiac arrest. ${ }^{7}$ Although short EMS response time is critical to successful resuscitation, the training of citizens in CPR expands the situations in which successful resuscitation can occur.

With the logistic model developed in this study, it

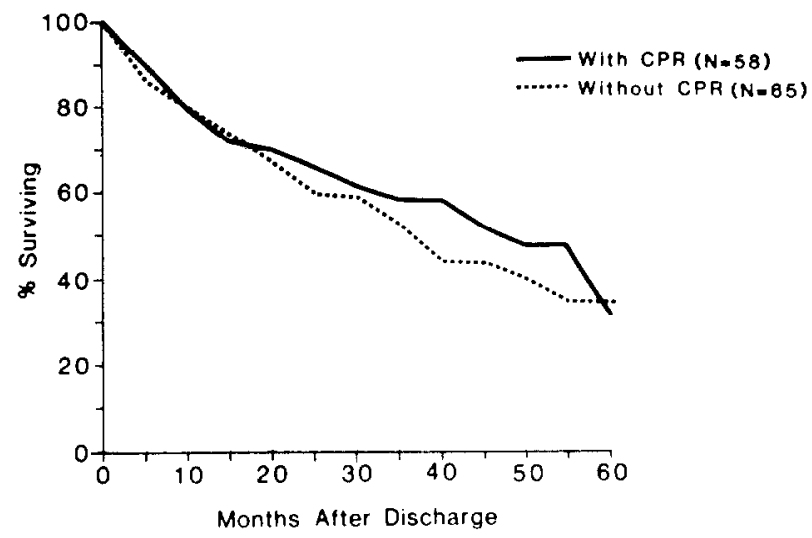

Fig. 3. The long-term postdischarge survival of 123 outof-hospital cardiac arrest victims. There was no significant difference between those with and without bystander CPR $(p>0.10)$.

is possible to evaluate a number of factors that influence survival. With the use of this model, patients who experience cardiac arrest after arrival of the EMS can be compared to hypothetical subjects who had a 0 -minute response time and received bystander CPR. In this comparison, the survival rates for patients who had the benefit of very early EMS arrival and CPR were similar to survival rates for patients whose cardiac arrest occurred in the presence of the EMS. Fig. 2 shows that the AAA survival rate is close to the position on the time scale that would be occupied by a 0 -minute EMS response time. Patients who receive CPR are more inclined to have ventricular fibrillation than patients who do not receive CPR. The increased incidence of ventricular fibrillation in victims of cardiac arrest who received CPR suggests a possible mechanism by which CPR affects survival.

A number of important factors affect successful resuscitation. When the patient experienced cardiac arrest at home, CPR rarely preceded the arrival of the EMS. The fact that more than half of the cardiac arrests occurred in patients over 60 years of age and in the home where other persons may not have been present adds logistic problems to the implementation of resuscitation systems. In addition, the younger members of society are exposed to CPR training and they are not usually in close contact with the elderly, who are most likely to require CPR. ${ }^{10}$ Universal training in CPR could help solve this problem. One group that should be targeted for training in CPR are companions of patients who have already experienced a myocardial infarction and individuals who are at high risk for other reasons. ${ }^{11}$ The EMS runs to the work place or to public places represent approximately one quarter of all the EMS runs. In 
our study, bystander CPR was often administered by health professionals-this fact emphasizes the need to broaden the base of CPR training of professional personnel. A similar observation was made by Murphy et al. ${ }^{10}$ This is also the group that would be most likely to retain the ability to perform CPR. Bystander CPR preceded the arrival of the EMS in almost half of the instances when the cardiac arrest occurred in a public place and in over $60 \%$ where cardiac arrests occurred at work. Although this is an impressive achievement when measured against the lack of CPR less than two decades ago, it indicates that there is still need for further improvement which could be gained by additional CPR training.

Thompson et al. ${ }^{6}$ suggested that bystander CPR had a greater effect on late posthospital survival than on early in-hospital survival. Salutary effects on both left ventricular dysfunction ${ }^{9}$ and central nervous system damage ${ }^{5}$ have been reported in patients receiving bystander CPR. We observed substantial effects of CPR on the early in-hospital survival rate and discharge rate. Eisenberg et al. ${ }^{8}$ observed that long-term survival following out-ofhospital cardiac arrest was not effected by the EMS response time or bystander CPR. Our observations also confirm that CPR failed to effect long-term survival.

The importance of geographic and demographic characteristics of communities upon survival rates achieved by EMS and CPR was emphasized by Guzy et al. They reported that the short response time of the EMS was the reason for higher success rates achieved in Seattle, as compared to rates achieved in Los Angeles. Our observations support this hypothesis but indicate that other variables are also important. Age is an important factor, reflecting not only the nature and duration of cardiac disease but also the relative social isolation of the over-65, retired population. This strongly suggests that communities of older individuals should develop different strategies when developing CPR programs than communities composed of a younger working population.

This study provides further support for the bene- fit of CPR coupled with EMS and provides a direction for future strategies to achieve maximum benefit from both of these programs. It is a fact that in communities where both CPR training and access to emergency medical care are readily available, improved patient survival after out-of-hospital cardiac arrest is a reality. In order to deal with the public health aspects of sudden death in the community, there must be greater emphasis on the development of critical strategies in both areas of emergency care.

We acknowledge the important contribution (1) this study by Mary Czajka, R.N., Karen McConnaughy, R.N.. and Connie Mattice, R.N., and to the Regional Emergency Services of Northeast Ohio, the Fire Department of Southtield, Michigan, and to the Emergency Medical Services of Kent County, Michigan.

\section{REFERENCES}

1. Kouwenhoven WB, Jude JR, Knickerbocker GG: Closed chest cardiac resuscitation. JAMA 173:1064, 1960.

2. Pantridge JF, Ceddes IS: Cardiac arrest after myocardial infarction. Lancet 1:807, 1966.

3. Grace WJ, Chadbourn JA: The mobile coronary care unit. Dis Chest 55:452, 1969.

4. Lewis AJ, Alcshieg G, Griley JM: Pre-hospital cardiac care-A paramedical mobile intensive care unit. Calif Med 117:1, 1972.

5. Lund I, Skulberg A: Cardiopulmonary resilscitation in lay people. Lancet 2:702, 1976.

6. Thompson RG. Hallstron AP, Cobb LA: Bystander initiated cardiopulmonary resuscitation in the management of ventricular fibrillation. Ann Intern Med 90:737, 1979.

7. Guzy P, Pearce M, Greenfield S: The survival benefit of bystander cardiopulmonary resuscitation in a paramedic served metropolitan area. Am \& Public Health 73:766. 1983.

8. Eisenberg M, Hallstrom A, Bergner L: Long-term survival after out-of-hospital cardiac arrest. N Engl I Med 306:1340. 1982.

9. Copley DP, Mantle JA, Rogers WJ, Russel RO Jr, Rackley CE: Improved outcome for prehospital cardiopulmonary collapse with resuscitation by bystanders. Circulation 56:901. 1977.

10. Murphy R, Lepker R, Jacobs D, Gillum R, Folsom A. Blackburn H: Citizen cardiopulmonary resuscitation training: and use in a metropolitan area: The Minnesuta Heart Survey, Am J Public Health 74:513, 1984.

11. Greene WA, Goldstein S, Moss AJ: Psychessocial aspects of sudden death. Arch Intern Med 129:725, 1972. 